\title{
Addendum: High-resolution specificity profiling and off-target prediction for site-specific DNA recombinases
}

\author{
Jeffrey L. Bessen (10) 1,2,3, Lena K. Afeyan1,2,3, Vlado Dančík ${ }^{4}$, Luke W. Koblan 1,2,3, David B. Thompson²,3, \\ Chas Leichner ${ }^{5}$, Paul A. Clemons (1) ${ }^{4}$ \& David R. Liu (1) ${ }^{1,2,3}$
}

Addendum to: Nature Communications https://doi.org/10.1038/s41467-019-09987-0, published online 26 April 2019.

The authors have become aware that 'BTR pseudo-site 2' inadvertently contains two incorrect nucleotides and does not match the sequence of the pseudo-site in the human genome. The data points corresponding to this construct in Fig. 5e and Supplementary Table 5 are therefore no longer valid. However, the overall conclusion that Rec-seq can predict the activity of site-specific recombinases on endogenous human genomic pseudo-sites of remains unaffected by this error. Updated versions of Fig. 5 and Supplementary Table 5 are presented below as Figures 1 and Table 1 respectively.

Published online: 02 July 2019

\footnotetext{
(c) (i) Open Access This article is licensed under a Creative Commons Attribution 4.0 International License, which permits use, sharing, adaptation, distribution and reproduction in any medium or format, as long as you give appropriate credit to the original author(s) and the source, provide a link to the Creative Commons license, and indicate if changes were made. The images or other third party material in this article are included in the article's Creative Commons license, unless indicated otherwise in a credit line to the material. If material is not included in the article's Creative Commons license and your intended use is not permitted by statutory regulation or exceeds the permitted use, you will need to obtain permission directly from the copyright holder. To view a copy of this license, visit http://creativecommons.org/licenses/by/4.0/.
}

(c) The Author(s) 2019

\footnotetext{
${ }^{1}$ Merkin Institute of Transformative Technologies in Healthcare, Broad Institute of Harvard and MIT, Cambridge, MA 02142, USA. ${ }^{2}$ Department of Chemistry and Chemical Biology, Harvard University, Cambridge, MA 02138, USA. ${ }^{3}$ Howard Hughes Medical Institute, Harvard University, Cambridge, MA 02138, USA. ${ }^{4}$ Chemical Biology and Therapeutics Science Program, Broad Institute of Harvard and MIT, Cambridge, MA 02142, USA. ${ }^{5}$ Google Inc., Mountain View, CA 94043, USA. Correspondence and requests for materials should be addressed to D.R.L. (email: drliu@fas.harvard.edu)
} 
a
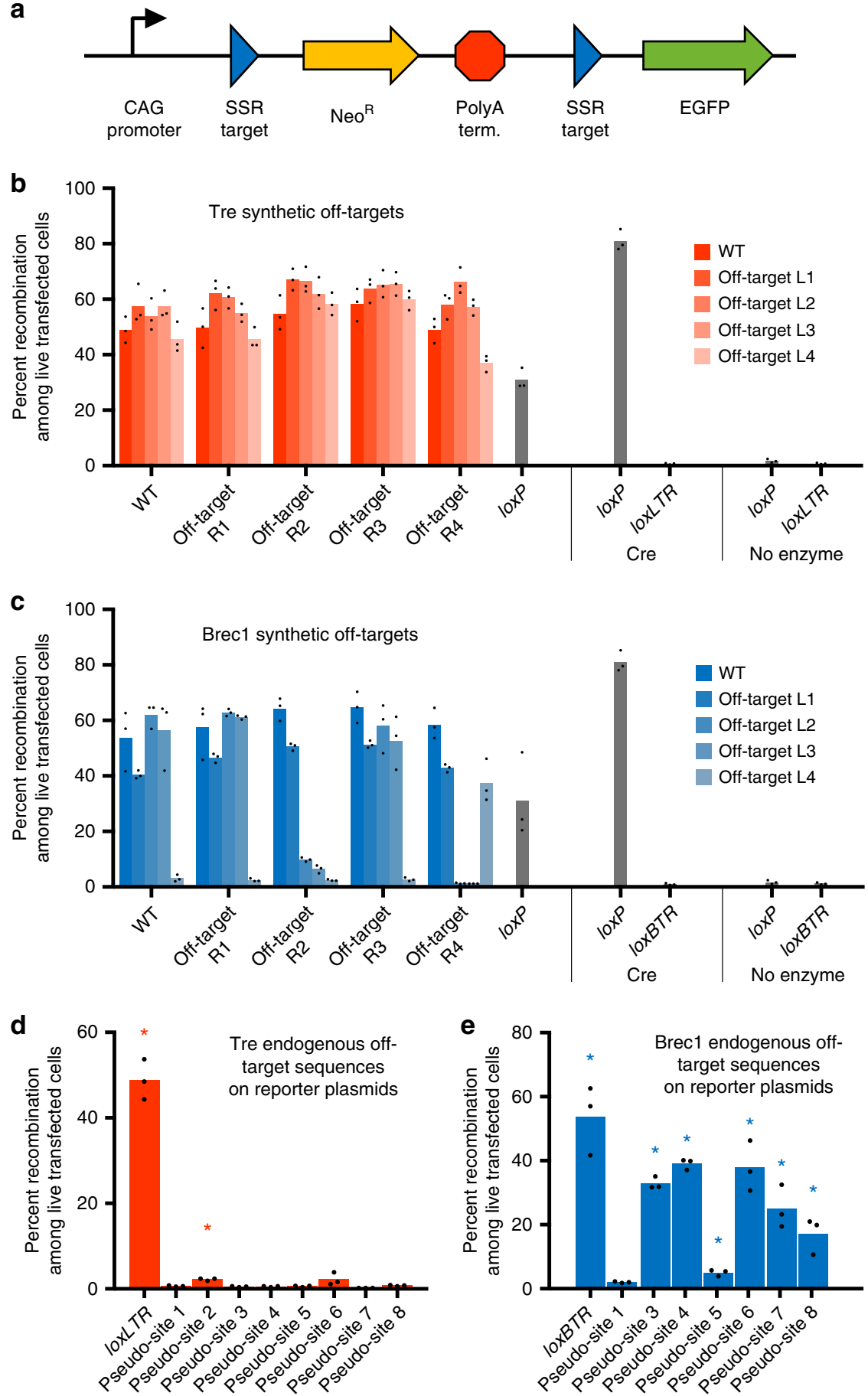

Fig. 1 
Table 1 Human genomic off-target substrates for Brec1

\begin{tabular}{|c|l|c|l|}
\hline Name & \multicolumn{1}{|c|}{ Sequence } & $\begin{array}{c}\text { Non-core } \\
\text { mismatches }\end{array}$ & \multicolumn{1}{c|}{ Genomic location } \\
\hline BTR & AACCCACTGCTTAAGCCTCAATAAAGCTTGCCTT & -- & -- \\
\hline BTR-off 1 & TATACACTGCTTACTAAGCTGTAAGACTTGGTGT & 8 & chr12 + 90808809 \\
\hline BTR-off 3 & CTCCCGCTGCTTACGTGTCTTTAAACCATGTTCC & 9 & chr1 - 159864674 \\
\hline BTR-off 4 & TCCATACAGGTTAGCATGTAATAAATCATGGCTT & 9 & chr3 - 167733225 \\
\hline BTR-off 5 & CCGGCGCTGCTTATTTCGGCCTAACTCTTGGTTT & 9 & chr4 + 13484892 \\
\hline BTR-off 6 & AACTGTCTGCTTAAGGAAATATAACTCTTGCTTT & 6 & chr7 - 125265273 \\
\hline BTR-off 7 & ATCAAACTGTTTAGTTTAGAATAAAACATGCTAT & 8 & 2 instances \\
\hline BTR-off 8 & AAAGGACTGGTTAACACCCCCTAATTCCTGCCCA & 9 & chr12 + 103496569 \\
\hline
\end{tabular}

Human genomic off-target Brec1. Mismatches relative to loxBTR (red) and core sequences (gray) are highlighted. 